ORIGINAL ARTICLE

\title{
Spray-dried chestnut extract containing Lactobacillus rhamnosus cells as novel ingredient for a probiotic chestnut mousse
}

\author{
A. Romano ${ }^{1}$, G. Blaiotta ${ }^{2}$, A. Di Cerbo ${ }^{3}$, R. Coppola ${ }^{4}$, P. Masi ${ }^{1,2}$ and M. Aponte ${ }^{2,4}$ \\ 1 Centre for Food Innovation and Development in the Food Industry, University of Naples Federico II, Portici, Naples, Italy \\ 2 Dipartimento di Agraria, Università degli Studi di Napoli Federico II, Portici, Naples, Italy \\ 3 Dipartimento di Chirurgia Generale e Specialità Chirurgiche, Università degli Studi di Modena e Reggio Emilia, Modena, Italy \\ 4 Istituto di Scienze dell'Alimentazione, ISA-CNR, Avellino, Italy
}

\section{Keywords}

chestnut extract, chestnut mousse, Lactobacillus rhamnosus, probiotic, spray drying.

\section{Correspondence \\ Maria Aponte, Dipartimento di Agraria, Uni- versità degli Studi di Napoli Federico II, Via Università 100, 80055 Portici, Naples, Italy. E-mail: aponte@unina.it}

2013/2293: received 14 November 2013, revised 14 January 2014 and accepted 3 February 2014

doi:10.1111/jam.12470

\begin{abstract}
Aims: Consumers' demand for innovative probiotic products has recently increased. In previous studies, chestnuts were evaluated as substrate for the growth of lactobacilli and chestnut extract was found to enhance acid tolerance of probiotic strains. The main objectives of this study were to evaluate the suitability of chestnut extract as carrier for spray drying of two probiotic Lactobacillus rhamnosus strains and to develop a probiotic food chestnut based.

Methods and Results: The optimal settings for the spray-drying processes were defined and the loads of undamaged cells in the dried powders were quantified. Spray-dried cultures were incorporated into an anhydrous basis for chestnut mousse developed ad hoc. In this form, viable cells remained stable over $10^{8} \mathrm{CFU} \mathrm{g}^{-1}$ during a 3 months long storage at $15^{\circ} \mathrm{C}$. Sensorial analysis did not highlighted significant differences $(P<0.05)$ in preference between probiotic-supplemented and control mousses.

Conclusions: Results suggest that chestnut mousse, a food product naturally rich in antioxidant compounds, may represent an excellent carrier for probiotics delivering.

Significance and Impact of the Study: To authors' knowledge, this is the first information on the survival of lactobacilli in an anhydrous basis for dessert.
\end{abstract}

\section{Introduction}

The use of foods that promote a state of well-being, better health and reduction in the risk of diseases has become popular as consumers become more health conscious (Mussatto and Mancilha 2007). Some good examples are foods containing physiologically active components such as probiotics and prebiotics. Probiotics are defined as "live micro-organisms which when administered in adequate amount confer health benefits to the host" (FAO/WHO 2002). At present, several well-characterized strains of lactobacilli and bifidobacteria are available for human use to reduce the risk of gastrointestinal trait (GIT) infections or treat such infections (Nagpal et al. 2012). Some of the beneficial effects of probiotic consumption include improvement in intestinal health by the regulation of microbiota, stimulation and development of the immune system, synthesizing and enhancing the bioavailability of nutrients, reducing symptoms of lactose intolerance, reducing the level of serum cholesterol and the risk of certain other diseases (Saarela et al. 2002).

The chemical composition of chestnut fruits have been recently reviewed (De Vasconcelos et al. 2010), revealing the presence of various nutrients that are important for human health. Chestnut fruits are mainly composed of carbohydrates: primarily starch. The free sugar sucrose can be up to one-third of the total sugars, but studies revealed the presence of several mono- and disaccharides 
(glucose, fructose, sucrose and maltose) as well as of fibre (De Vasconcelos et al. 2010). On the other hand, chestnuts contain very small amounts of crude fat content that is low in saturated fatty acids and high in monounsaturated (MUFA) and polyunsaturated (PUFA) fatty acids, which are known for their anticancer effects and for decreasing the risk of cardiovascular diseases and neurological function disorders. Chestnut fruits also contain significant amounts of $\gamma$-aminobutyric acid and are a good dietary source of vitamins E, C, B1, B2, B3, pantothenic acid, pyridoxine, folate and of important mineral macroelements ( $\mathrm{Ca}, \mathrm{P}, \mathrm{K}, \mathrm{Mg}$ and $\mathrm{S}$ ) and microelements ( $\mathrm{Fe}, \mathrm{Cu}, \mathrm{Zn}$ and $\mathrm{Mn}$ ). Moreover, the chestnut fruit content of phenolics (gallic and ellagic acid) has been linked with various positive health effects such as antioxidant effects, decreases in the risk of cardiovascular diseases, anticancer mechanisms and anti-inflammatory properties (De Vasconcelos et al. 2010). Moreover, chestnut fruits do not contain gluten, and thus, there are many new products derived from chestnuts and chestnut flour that have been created to replace wheat-/cereal-containing foods (Aponte et al. 2013).

In previous studies, chestnut puree was evaluated as substrate for the growth of probiotic strains (Blaiotta et al. 2012), and chestnut extract was found to enhance acid tolerance and bile tolerance (Blaiotta et al. 2013), two fundamental properties that indicate the ability of a probiotic micro-organism to survive the passage through the GIT (Ranadheera et al. 2010). In detail, RP-HPLC highlighted the presence in the chestnut extract obtained by cultivar 'Castagna di Montella', of one or more hydrophobic peptides, which specifically offer a marked resistance to simulated gastric juice (Blaiotta et al. 2013).

Probiotics are commonly found in chilled short shelflife foods, such as fermented milk drinks, but the consumer's demand for healthy foods in a variety of formats is increasing (Chávez and Ledeboer 2007). Particularly, there is a growing interest in including viable probiotics in dried foods with a long-term ambient shelf life, and in sufficient numbers to provide a health benefit, allegedly more than $10^{8} \mathrm{CFU}$ per serving or $10^{6}-10^{8} \mathrm{CFU} \mathrm{g} \mathrm{g}^{-1}$ of food (FAO/WHO 2002). In such optic, the objectives of the current study were (i) to examine the effect of chestnut extract on the viability after spray drying of two Lactobacillus (Lact.) rhamnosus strains: probiotic LbGG (ATCC 53103) and RBM526 isolated from Parmigiano Reggiano cheese, which has shown high survival under GIT conditions in previous reports (Blaiotta et al. 2012, 2013), (ii) to evaluate shelf life and sensorial profile of chestnut mousses obtained by means of incorporation of dried lactobacilli in chestnut extract into an anhydrous basis.

\section{Materials and methods}

\section{Micro-organisms and culture conditions}

Strains used in this study were Lact. rhamnosus RBM526 isolated from Parmigiano Reggiano cheese (Blaiotta et al. 2012, 2013) and Lact. rhamnosus GG from ATCC (ATCC 53103). Strains were cultivated in MRS (Oxoid, Basingstoke, UK) at $37^{\circ} \mathrm{C}$. For long term, cultures were stored at $-80^{\circ} \mathrm{C}$ in MRS broth containing $25 \%$ glycerol (Sigma, Milan, Italy).

\section{Effect of chestnut fibre and chestnut extract on the strains' tolerance to simulated gastric juice}

The tolerance of lactobacilli to simulated gastric juice was determined according to a procedure previously detailed (Blaiotta et al. 2013). Briefly, for the preparation of the chestnut medium (CM), $5 \mathrm{~g}$ of chestnut flour from cv 'Castagna di Montella' was mixed with $95 \mathrm{ml}$ of distilled water under heating at $80^{\circ} \mathrm{C}$ for $20 \mathrm{~min}$ and sterilized at $121^{\circ} \mathrm{C}$ for $20 \mathrm{~min}$ before use. The chestnut extract (CE) was prepared by centrifuging $(8.160 \mathrm{~g}, 10 \mathrm{~min}) \mathrm{CM}$ to separate solids ( $\mathrm{pH}$ of CE $5 \cdot 75 \pm 0 \cdot 20)$. To assess viability, overnight cultures in MRS were centrifuged $(8.160 \mathrm{~g}$, $10 \mathrm{~min})$, after washing twice with sterile saline $(0 \cdot 5 \%$, wt $\left.\mathrm{vol}^{-1}\right)$. The pellets were resuspended in the same saline $(0.2 \mathrm{ml})$, mixed with simulated gastric juice $(1 \mathrm{ml})$, and CE or sterile saline $(0.3 \mathrm{ml})$ as control. Simulated gastric juices were daily prepared by suspending pepsin ( $1: 10000$, ICN, Sigma) in sterile saline $\left(0 \cdot 5 \%\right.$, wt $\left.\mathrm{vol}^{-1}\right)$ to a final concentration of $3 \mathrm{~g} \mathrm{l}^{-1}$ and adjusting the $\mathrm{pH}$ to 2.00 with concentrated $\mathrm{HCl}$ using a $\mathrm{pH}$ meter. Aliquots were taken, during incubation at $37^{\circ} \mathrm{C}$, after $0,15,30$, 60, 90 and $180 \mathrm{~min}$ for gastric tolerance measurements.

\section{Spray drying}

\section{Heat challenge experiments}

The thermal tolerance of strains was compared in three different conditions: (i) cells in stationary phase of growth from MRS were harvested by centrifugation $(8.160 \mathrm{~g}, 10 \mathrm{~min})$, washed in Ringer's solution (Oxoid) and resuspended, at the same ratio, in CE (around $4 \%$ solid content) or alternatively (ii) in filter-sterilized trehalose (Sigma) solution (20\% wt vol $\left.{ }^{-1}\right)$; (iii) cells in stationary phase of growth from $\mathrm{CM}$ were collected by centrifugation, washed and resuspended in CE $(1: 1)$. In all cases, samples $(2 \mathrm{ml})$ were put into sterile A-R glass capillaries (Kleinfeld Labortechnik GmbH, Gehrden, Germany) and placed in a water bath at the test temperatures of 60,65 and $70^{\circ} \mathrm{C}$. At 30-s intervals $(0,30,60,90$, 120, 150, 180, 210 and $240 \mathrm{~s}$ ), capillaries were removed 
and cooled in ice bath, after which a sample volume of $100 \mu \mathrm{l}$ was serially diluted in Ringer's solution and dropplated on MRS agar (Collins et al. 1989). Survivors were enumerated after $48 \mathrm{~h}$ of anaerobic incubation at $37^{\circ} \mathrm{C}$ (Anaerogen $^{\mathrm{TM}}$, Oxoid).

\section{Drying process}

The spray-drying process of Lact. rhamnosus strains was undertaken in a laboratory scale spray dryer (B-191; Büchi, Milan, Italy). Strains were grown in MRS medium (1 1 ) at $37^{\circ} \mathrm{C}$ up to the stationary phase. After centrifugation, cells were washed with Ringer's solution and resuspended $(1: 1)$ in $\mathrm{CE}$ (about $10^{9} \mathrm{CFU} \mathrm{g}^{-1}$ ). The feed solution was pneumatically atomized into a vertical, cocurrent drying chamber using a two-fluid nozzle $(0.7 \mathrm{~mm})$. The outlet temperature was adjusted from 60 to $75^{\circ} \mathrm{C}$ by varying the flow rate. The following combinations inlet/outlet temperatures were evaluated: $140 / 60^{\circ} \mathrm{C}$, $140 / 65^{\circ} \mathrm{C} 140 / 70^{\circ} \mathrm{C}$ and $130 / 65^{\circ} \mathrm{C}$. The dried powders were collected in a product container connected at the bottom of the single cyclone separator.

\section{Determination of moisture content of dried samples}

The residual moisture content of spray-dried samples was determined by oven-drying the powders at $105^{\circ} \mathrm{C}$, determining the difference in weight and expressing the weight loss as a percentage of the initial powder weight (International Dairy Federation Standard 1993).

\section{Enumeration of lactobacilli after spray drying}

To determine the survival rate of the strains, $1 \mathrm{~g}$ spraydried powders were rehydrated $(1: 10)$ in sterile Ringer solution, serially diluted and plated in duplicate on MRS agar. Plates were incubated anaerobically (Anaerogen ${ }^{\mathrm{TM}}$ ) at $37^{\circ} \mathrm{C}$ for $48 \mathrm{~h}$, a period at which countable colonies were observed.

\section{Sensitivity test}

To quantify the cellular damage arising from the spraydrying process, the sensitivity of cultures to $\mathrm{NaCl}$, before and after drying processes, was evaluated (Gardiner et al. 2000). To select the adequate $\mathrm{NaCl}$ concentration, the minimum inhibitory concentration (MIC) was determined, and subinhibitory concentration was used. To assess MIC, strains were grown in MRS broth with increasing salt contents $(4,5,6,7,8,9,10$ and $12 \%)$. After $24 \mathrm{~h}$ of incubation, O.D. values were measured at a wavelength of $595 \mathrm{~nm}$ and compared with cultures in MRS without $\mathrm{NaCl}$. Not fatally injured cells were thus evaluated by plating on MRS agar plates supplemented with $8 \% \mathrm{NaCl}$. The plates were examined after 3 and 5 days of anaerobic incubation, and viable numbers were compared with numbers obtained by counting on MRS without $\mathrm{NaCl}$.
On samples processed in the best conditions, namely at a constant air inlet temperature of $140^{\circ} \mathrm{C}$, outlet temperature of $65^{\circ} \mathrm{C}$ and flow rate of $4.5 \mathrm{ml} \mathrm{min}{ }^{-1}$, bacterial viability per gram was assessed using in parallel: direct counting at microscope in Petroff-Hausser chamber (total cells), live/dead ${ }^{\circledR}$ BacLight $^{\mathrm{TM}}$ Bacterial Viability Kit (Molecular Probes, Eugene, OR) followed by epifluorescence microscope observation, plating onto MRS agar after incubation at $37^{\circ} \mathrm{C}$ for $48 \mathrm{~h}$ (living cells) and MRS agar supplemented with $8 \%$ after 5 days of incubation $\mathrm{NaCl}$ (not fatally injured cells). For the fluorescence microscopy test, cells were dyed using two fluorochromes SYTO 9 (green dye: undamaged cells) and propidium iodide (red dye: dead or injured cells). After staining followed by incubation in the dark for $15 \mathrm{~min}$ at room temperature, samples were observed using a Nikon Eclipse E400 epifluorescence microscope (Nikon, Tokyo, Japan) equipped with a UV lamp and $\mathrm{a} \times 100$ magnification objective. Images were captured by a Nikon Coolpix 4500 Digital Camera equipped with a microscope adapter.

To evaluate the survival to simulated gastric juice, powders $(0.5 \mathrm{~g})$ were resuspended $\left(1 / 1 \mathrm{wt} \mathrm{vol}^{-1}\right)$ in sterile saline solution and added of simulated gastric juice ( $1 \mathrm{ml}$ ); afterwards, the same procedure detailed above was repeated.

\section{Production of chestnut mousse}

\section{Ingredients for mousse}

Chestnut flour from cv 'Castagna di Montella', as well as ingredients for chestnut mousse, was kindly provided by Ipafood srl company (Frigento, Avellino, Italy). All components used in the preparation of laboratory mousses are listed in Table 1.

Mousse- making procedure

Pilot-scale anhydrous formulations for chestnut mousses were produced in triplicate in collaboration with Ipafood.

Table 1 Composition of the anhydrous basis for chestnut mousses

\begin{tabular}{lc}
\hline Ingredients & $\mathrm{g} \mathrm{kg}^{-1}$ \\
\hline Chestnut flour & 300 \\
Hydrogenated coconut fat & 150 \\
Cocoa powder & 100 \\
Sucrose & 150 \\
Maize starch & 100 \\
Modified starch & 30 \\
Milk proteins & 50 \\
Potato starch & 10 \\
Glucose syrup & 40 \\
Mono- and diglycerides of fatty acids & 15 \\
Carrageenan & 40 \\
Guar gum & 15 \\
\hline
\end{tabular}


Spray-dried cultures in CE of each tested strain were separately added to the mousse powder $\left(1 \% \mathrm{wt} \mathrm{wt}^{-1}\right)$ to obtain concentrations of approximately $9 \log \mathrm{CFU} \mathrm{g} \mathrm{g}^{-1}$ of living and undamaged cells in the final product. In detail, three mousse bases were produced: probiotic $(\mathrm{P})$ supplemented with strain LbGG, functional (F) supplemented with strain RBM526 and control (C) without bacterial strains. Samples were weighed, packaged in heat-sealed plastic aluminium foil bags (35 $\mathrm{g}$ each) and stored at $15 \pm 1^{\circ} \mathrm{C}$ for up to 120 days. Viability of lactobacilli in chestnut mousses $\mathrm{P}$ and $\mathrm{F}$ was monitored during the storage in two replicate trials. Monthly, samples were rehydrated with sterile deionized water $\left(100 \mathrm{ml} 35 \mathrm{~g}^{-1}\right)$, and viable counts were carried on using MRS agar.

All samples were made from the same model cream. For preparation, $35 \mathrm{~g}$ of mousse powder and $100 \mathrm{ml}$ of cold milk were mixed in a planetary kneader (KitchenAid KSM150PSMC Artisan, Denver, CO), equipped with a 4.800-L bowl, on medium speed for $1 \mathrm{~min}$, followed by $2 \mathrm{~min}$ at high speed. After chill at $4^{\circ} \mathrm{C}$ for $2 \mathrm{~h}$, chestnut mousse was ready to be consumed. Each lot of chestnut mousse was produced in amounts to obtain $2-3 \mathrm{~kg}$ of the final product.

\section{Descriptive sensory analysis}

Chestnut mousse samples (trials C, P and F) were analysed by a descriptive panel of 10 expert assessors (seven males and three females, aged between 25 and 55 years) with experience in sensory analysis (UNI 10957 2003). Samples $(40 \mathrm{ml})$ were presented in white plastic cups. Unsalted biscuits and warm water were used to rinse mouth between evaluations of the samples. The judges were trained in three preliminary sessions using different samples of commercial chocolate mousses, to develop a common vocabulary for the description of the sensory attributes of chestnut mousses samples and to familiarize themselves with scales and procedures. The judges generated sensory terms individually. Each attribute term was extensively described and explained to avoid any doubt about the relevant meaning. Finally, sixteen attributes were selected by consensus (the frequency of citation $>60 \%)$ to describe the mousse sample: intensity of the brown colour, compactness (Aspect); odour intensity, cocoa odour, vanilla odour, chestnut odour (Odour); cocoa flavour, chestnut flavour, taste intensity, sweet, astringency, bitter, bitter aftertaste (Gustative sensorial profile); texture, creamy, melting (Tactile) and overall impression.

The panellists used a $10-\mathrm{cm}$ structured scale to rate the intensity of each attribute. Random samples were evaluated by assigning a score between 1 (absence of the sensation) and 9 (extremely intense) in individual booths under incandescent white lighting at the sensory laboratory of the CAISIAL (Portici, Naples). A computerized data collection program was used (FIZZ, Software Solutions for Sensory Analysis and Consumer Tests, Biosystemes, Couternon, France). The mean of 10 evaluations was reported.

\section{Statistical analyses}

Statistical analysis was performed using SPSS, version 17.0 (SPSS Inc., Chicago, IL). The Duncan's multiple comparison test was applied to discriminate amongst the means of descriptive sensory data at the $95 \%$ confidence level $(P \leq 0 \cdot 05)$. Results were expressed as means and standard deviation of at least three independent experiments.

\section{Results}

\section{Thermal tolerance of probiotic strains}

According to heat-resistance tests, LGG and RBM526 strains did not significantly differ $(P>0.05)$ in their ability to survive at all treatment temperatures (data not shown). First of all, the maximum population level of both strains in CM appeared almost one log lower if compared with the growth exhibited in MRS medium (data not shown). When strains were heat-treated at $60^{\circ} \mathrm{C}$ for $30 \mathrm{~s}$, a reduction in the cell numbers, to about $3.70 \log \mathrm{CFU} \mathrm{m} \mathrm{m}^{-1}$, was recorded in all cases. When temperature was increased to $70^{\circ} \mathrm{C}$, a completely different trend could be observed: after $240 \mathrm{~s}$, the population levels, if strains were grown in MRS and resuspended in CE,

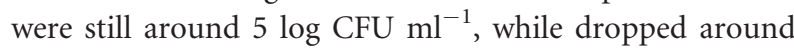
$2 \log \mathrm{CFU} \mathrm{m} \mathrm{m}^{-1}$ for strains resuspended in trehalose solution, as well as in $\mathrm{CE}$, if strains were grown in CM instead of MRS (data not shown).

\section{Survival rates during spray drying}

Preliminary spray-drying experiments were conducted to determine the optimal thermal levels for probiotic viability and to obtain powders with moisture contents of $\sim 3.5 \%$. According to data reported in Fig. 1, for the high water content, coupled with a troublesome stickiness of the powder, the combination inlet/outlet temperature $135 / 65^{\circ} \mathrm{C}$ could not be further considered, in spite of the recorded high survival rates $(56.53$ and $52.63 \%$ for LbGG and RBM526, respectively). In the other three combinations, the residual moisture content was seen to decrease as the inlet air temperature increased, from 2.84 to $1.81 \%$ and 2.75 to $1.91 \%$, for LbGG and RBM526, respectively (wt $\mathrm{wt}^{-1}$; Fig. 1). Following spray drying, the probiotic strains became sensitive to $\mathrm{NaCl}$, as revealed by decreases in cell numbers in the presence of salt. With 

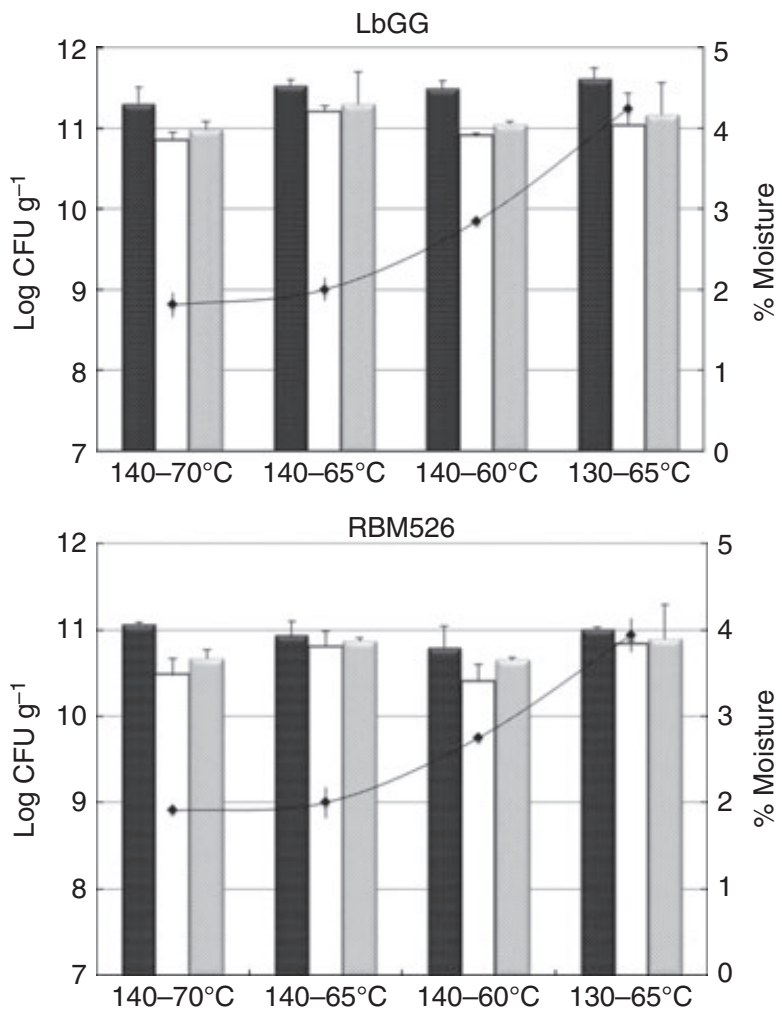

Figure 1 Viable counts and cell damage, indicated by sensitivity to $\mathrm{NaCl}$ (log CFU g ${ }^{-1}$ ), of spray-dried cultures (Lactobacillus rhamnosus GG and RBM526) in chestnut extract at different inlet and outlet air temperatures. The line indicates the moisture contents of resulting powders. The results are means based on data from three spray-drying trials ( \pm SD). ( MRS; $\square$ MRS $8 \% \mathrm{NaCl} 5 \mathrm{~g}$; (rum:a) MRS $8 \%$ $\mathrm{NaCl} 7 \mathrm{~g}$ and $(\multimap-) \%$ moisture.

inlet fixed at $140^{\circ} \mathrm{C}$, the percentage of not fatally damaged cells, by counting on MRS NaCl-added after 5 days of incubation, appeared significantly higher $(P<0.05)$ at an outlet temperature of $65^{\circ} \mathrm{C}$, so the combination $140 / 65^{\circ} \mathrm{C}$ was used for further assessments.

To get the most reliable quantification of the cells not injured by the heat exposure, a parallel approach was adopted. For cells spray-dried at a constant air inlet temperature of $140^{\circ} \mathrm{C}$, outlet temperature of $65^{\circ} \mathrm{C}$ and flow rate of $4.5 \mathrm{ml} \mathrm{min}{ }^{-1}$, bacterial viability per gram of dried powders was evaluated. In detail, total cells were obtained by direct counting at the microscope, alive cells were quantified by counting on MRS agar plates, undamaged cells were obtained as green cells by Live/Dead BacLight Kit and by counting on MRS agar plated added of $\mathrm{NaCl}$, while the sum of damaged and dead cells was obtained by Live/Dead BacLight Kit (red cells; Fig. 2). Quantification of undamaged cells by MRS salt-added counting provided the same result of Live/Dead staining (Fig. 2). In other words, over $10^{11}$ cells $\mathrm{g}^{-1}$ (survival rate of about $50 \%)$, still presented a whole membrane.
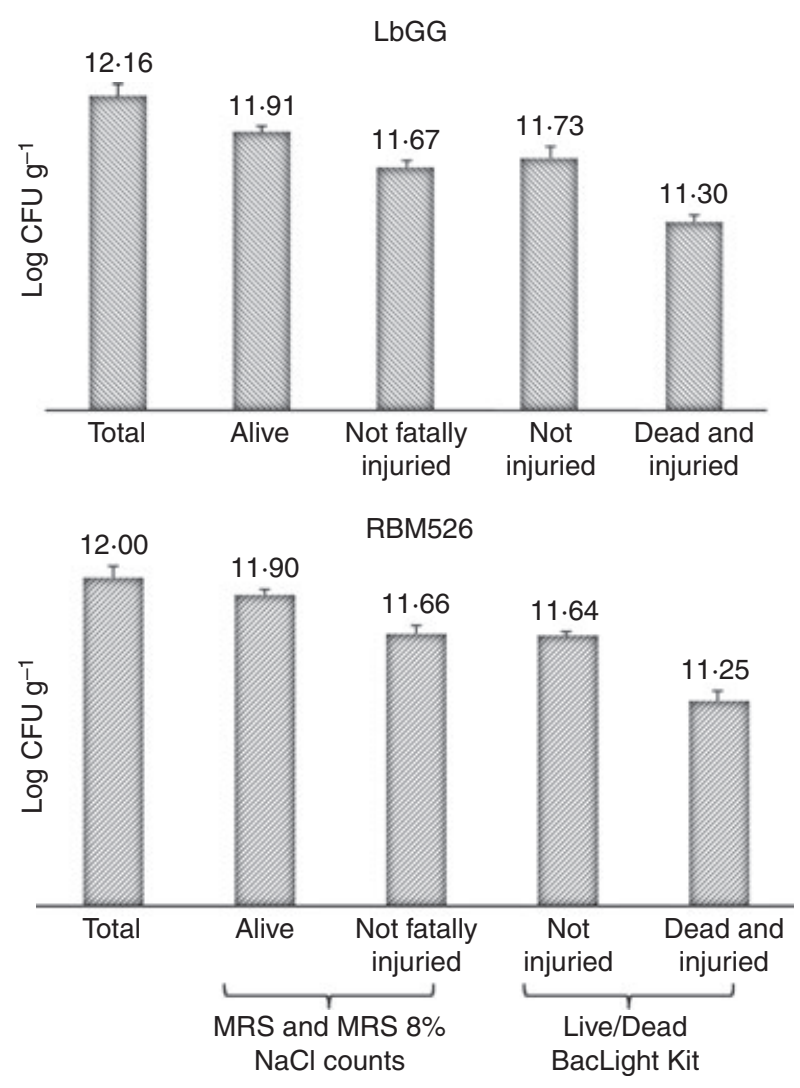

Figure 2 Viability ( $\log$ CFU g ${ }^{-1}$ ) of Lactobacillus rhamnosus strains (LGG and RBM526) after spray-drying experiments at an inlet temperature of $140^{\circ} \mathrm{C}$, an outlet temperature of $65^{\circ} \mathrm{C}$ and a flow rate of $4.5 \mathrm{ml} \mathrm{min}{ }^{-1}$. Results are means on triplicate trials ( $\pm S D$ ).

Both strains were able to survive in simulated gastric juice (Fig. 3). The number of cells able to stand the acidic environment was the same obtained by undamaged cells quantification, namely around $11 \log \mathrm{CFU} \mathrm{g} \mathrm{g}^{-1}$.

\section{Development of chestnut mousses enriched with functional lactobacilli}

Loads of Lact. rhamnosus LbGG and RBM526 in the anhydrous basis for chestnut mousse were initially 8.74 and $8.33 \log$ CFU g ${ }^{-1}$, respectively (Fig. 4). A loss of viability was detected; nevertheless, both strains maintained a population level above $8 \log \mathrm{CFU} \mathrm{g}^{-1}$, during the first 90 days of monitoring (Fig. 4).

To evaluate the potential effect of lactobacilli and CE on sensorial profile of chestnut mousse, sensorial analyses of the three kinds of chestnut-based mousses ( $\mathrm{P}, \mathrm{F}$ and C) were carried out. Table 2 shows the mean scores of the sensory attributes selected by descriptive sensorial analysis to describe the samples and the overall acceptance of the experimental mousses. Only five descriptors (compactness, cocoa odour, taste intensity, sweet and 


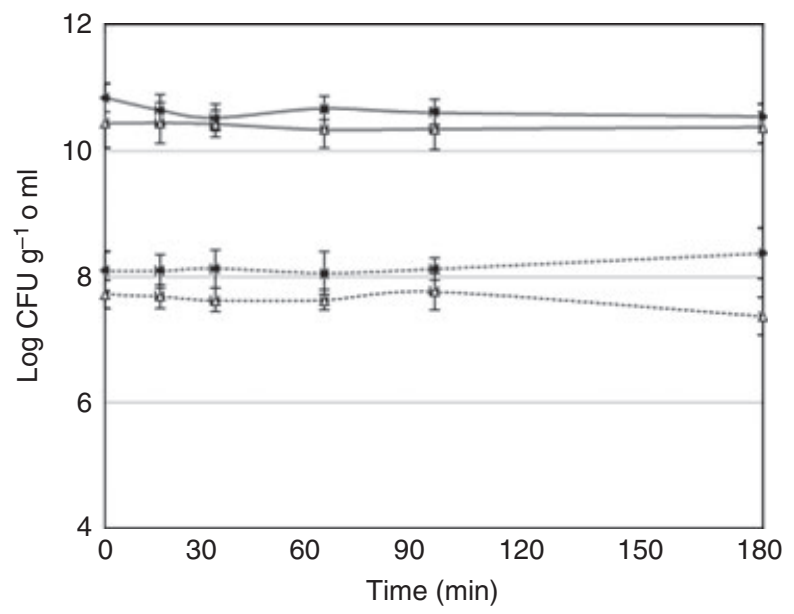

Figure 3 Viability of Lactobacillus rhamnosus strains (LGG and RBM526) in presence of fresh chestnut extract (dashed lines) and as spray-dried cells in chestnut extract (continuous lines) during $180 \mathrm{~min}$ of incubation in presence of simulated gastric juice. Values are means of three determinations $( \pm$ SD). $(\bullet-)$ LbGG; $(\bullet)$ LbGG spray dried; $\left(-\triangle^{-}\right)$RBM526 and $\left(-\triangle^{-}\right)$RBM526 spray dried.

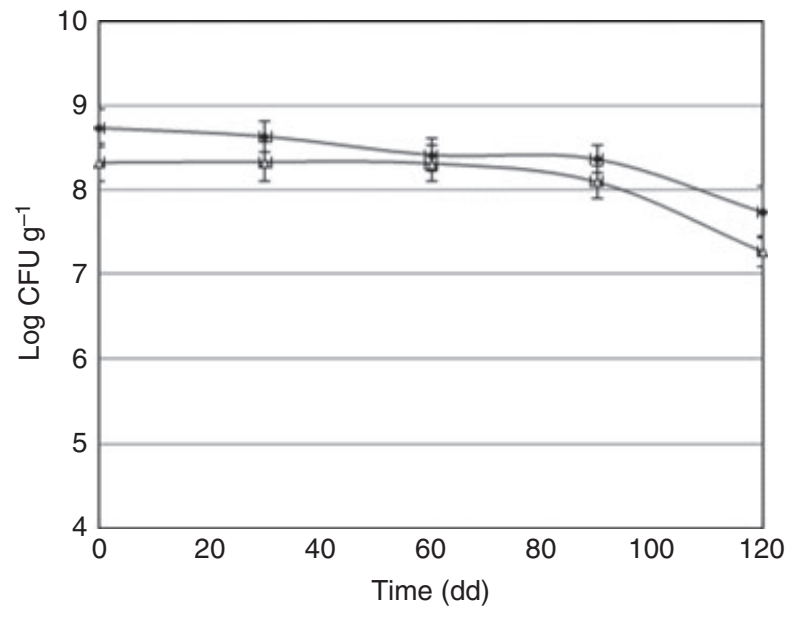

Figure 4 Viability of spray dried Lactobacillus rhamnosus strains, ( $\bullet$ LGG and $(\triangle)$ RBM526, in chestnut mousses during storage at $15^{\circ} \mathrm{C}$. Data are the means of three replicate storage trials $( \pm S D)$.

texture) significantly varied $(P<0 \cdot 05)$ within mousses samples (Table 2). With reference to samples aspect, only insignificant colour differences could be observed, while it was possible to discriminate $\mathrm{C}$ and $\mathrm{F}$ samples for compactness $(P<0.05)$. When focusing on odour and taste, all chestnut mousses were characterized by a cocoa flavour (4.5-6.6 mean intensity ratings) and taste intensity (6.4-7.3 mean intensity ratings). Lower but detectable levels of vanilla and chestnut flavours $(<4.6$ ratings) were perceived. Creamy and melting descriptors were not statistically different $(P<0.05)$, indicating that living
Table 2 Sensorial descriptors mean scores and standard deviations of chestnut mousses: control $(C)$, probiotic mousse $(P)$ and functional mousse (F)

\begin{tabular}{|c|c|c|c|}
\hline & C & $P$ & $\mathrm{~F}$ \\
\hline \multicolumn{4}{|l|}{ Aspect } \\
\hline Brown colour & $3.63^{a} \pm 1.40$ & $3.88^{a} \pm 1.73$ & $3.88^{a} \pm 2.03$ \\
\hline Compactness & $7.25^{b} \pm 0.89$ & $6.75^{a, b} \pm 1.67$ & $6.00^{a} \pm 0.93$ \\
\hline \multicolumn{4}{|l|}{ Odour } \\
\hline Intensity & $6 \cdot 88^{a} \pm 1 \cdot 13$ & $6 \cdot 25^{a} \pm 1 \cdot 28$ & $6.50^{a} \pm 0.93$ \\
\hline Cocoa & $6.63^{b} \pm 1.69$ & $5.50^{a} \pm 0.93$ & $6.38^{b} \pm 1.41$ \\
\hline Vanilla & $4.63^{a} \pm 1.92$ & $3.50^{a} \pm 2.07$ & $3.88^{a} \pm 2.42$ \\
\hline Chestnut & $4.25^{a} \pm 2.05$ & $4 \cdot 16^{a} \pm 1.46$ & $4.25^{a} \pm 1.04$ \\
\hline \multicolumn{4}{|l|}{ Gustative } \\
\hline Cocoa & $6 \cdot 38^{a} \pm 1 \cdot 19$ & $6.13^{a} \pm 0.83$ & $6.13^{a} \pm 1.46$ \\
\hline Chestnut & $4.50^{a} \pm 2.45$ & $5.00^{a} \pm 2.00$ & $5 \cdot 00^{a} \pm 2 \cdot 20$ \\
\hline Taste intensity & $7 \cdot 25^{b} \pm 1 \cdot 16$ & $6 \cdot 38^{a} \pm 0.52$ & $6.88^{a, b} \pm 0.83$ \\
\hline Sweet & $6 \cdot 38^{a} \pm 1.41$ & $7.25^{b} \pm 1.04$ & $6 \cdot 00^{\mathrm{a}} \pm 1.51$ \\
\hline Astringency & $3.25^{a} \pm 1.28$ & $2 \cdot 50^{a} \pm 1 \cdot 20$ & $3.00^{a} \pm 1.60$ \\
\hline Bitter & $2 \cdot 75^{a} \pm 1.39$ & $3 \cdot 38^{a} \pm 1 \cdot 60$ & $3.75^{a} \pm 1.49$ \\
\hline Bitter aftertaste & $2 \cdot 63^{a} \pm 1.19$ & $2.38^{a} \pm 0.74$ & $3.00^{a} \pm 1.41$ \\
\hline \multicolumn{4}{|l|}{ Tactile } \\
\hline $\begin{array}{l}\text { Texture } \\
\text { (soft/hard) }\end{array}$ & $7 \cdot 38^{b} \pm 1 \cdot 51$ & $6.63^{a, b} \pm 1.92$ & $5 \cdot 50^{a} \pm 1.93$ \\
\hline Creamy & $5.75^{a} \pm 2 \cdot 25$ & $6 \cdot 63^{a} \pm 1 \cdot 19$ & $5.38^{a} \pm 2.39$ \\
\hline Melting & $6 \cdot 88^{a} \pm 1 \cdot 13$ & $6 \cdot 13^{a} \pm 1.89$ & $5.88^{a} \pm 1.46$ \\
\hline Overall impression & $7 \cdot 38^{a} \pm 1 \cdot 51$ & $6.88^{a} \pm 0.35$ & $7 \cdot 13^{a} \pm 1 \cdot 13$ \\
\hline
\end{tabular}

Values with different letters in the same row indicate statistical differences according to the Duncan's test at $P<0.05$.

supplements (strain LbGG or RBM526) did not exert negative effect. Similarly, no significant difference was observed for overall impression, exhibiting in all cases a good range of evaluation ( $>6.5$ ratings).

\section{Discussion}

Probiotic cultures must be capable of withstanding the harsh conditions often encountered during food processing, to be successfully used in functional food applications. Preservation of micro-organisms by spray drying is a convenient, fast and widely used method for producing large quantities of bacterial probiotic cultures (Silva et al. 2011). In the first phase, this study compared the performance of two lactobacilli during spray drying and sought to enhance strains viability by comparing performance of cultures in presence of different substances during spray drying as well as by optimizing the parameters of the heat process. Initially, the thermal tolerance, an indicator of probiotic survival during spray drying (Gardiner et al. 2000), an indicator of the two probiotic lactobacilli was compared in three conditions, with resuspension in $20 \%$ trehalose as control. Undeniably, values for counts in trehalose of Lact. rhamnosus GG appeared in good 
agreement with those obtained by Sunny-Roberts and Knorr (2009) for the same strain. With temperature increasing $\left(70^{\circ} \mathrm{C}\right)$, promising results were recorded when strains were grown in MRS and resuspended in CE. Actually, for preserving the function of micro-organisms in the dry state, sucrose and trehalose have been utilized the most (Ying et al. 2012), although other sugars (e.g. maltose and fructose) and sugar alcohols (e.g. sorbitol and inositol) may offer protective effects as well (Ying et al. 2012). As matter of fact, according to previous studies, $\mathrm{CE}$, above all if produced with flour from the cv 'Castagna di Montella', is highly rich in reducing sugars and small peptides (Blaiotta et al. 2012, 2013) and, it is well documented that carbohydrates have protective effects for probiotic bacteria during drying (Corcoran et al. 2004). Surprisingly, no advantage was recorded when strains were cultivated in CM instead of MRS. Actually, the presence of protectants in the media, prior to fermentation, generally leads to an adaptation of probiotics to the environment, as compatible compounds accumulate within the cells, and the osmotic difference between the internal and external environments is reduced (Meng et al. 2008).

Apart from the survival rate, the main concern about spray drying is still the integrity of the cell that may be compromised by the exposure to high temperatures (Silva et al. 2011). As a matter of fact, this process may affect a large number of cellular components, including DNA, RNA, cytoplasmic membrane and cell wall (Santivarangkna et al. 2008). Because some probiotic properties are closely related to the structure of the bacterial surface, in the light of the further applications of the strains, it was of primary relevance to evaluate the cellular injury after treatment and to quantify the loads of undamaged cells, rather than the sole survival rate. Absolute viable counts are rarely provided in manuscripts focused on drying of cultures (Corcoran et al. 2004; Ananta et al. 2005; Chávez and Ledeboer 2007), but if the aim of the survey is, as in this case, the employment of the strains for the production of probiotic food, the number of viable bacteria must be properly quantified and has to fall within the range recommended to potentially obtain a health benefit in the finished product.

Preliminary spray-drying experiments allowed setting the optimum of heat conditions for probiotic viability, namely a constant air inlet temperature of $140^{\circ} \mathrm{C}$, an outlet temperature of $65^{\circ} \mathrm{C}$ and a flow rate of $4.5 \mathrm{ml} \mathrm{min}^{-1}$. In these conditions, the obtained powders presented a moisture content around $2 \cdot 0 \%$, well below $3 \cdot 5 \%$, namely the level regarded as a good quality parameter of dried products for prolonged storage and stability (Zayed and Roos 2004). As expected, following spray drying, the probiotic strains became sensitive to $\mathrm{NaCl}$, as revealed by decreases in cell numbers in the presence of salt. In general terms, growth in media supplemented with $\mathrm{NaCl}$ showed that injured cells were able to resuscitate. In fact, differences in cell counts between media with and without $\mathrm{NaCl}$ appeared lessened after prolonged incubation, as already reported in a previous survey (Mauriello et al. 1999). This suggested that cell membranes were damaged by the drying process, thus resulting in lower survival (Teixeira et al. 1996). Obtained data were similar to those reported by Gardiner et al. (2000) and Sunny-Roberts and Knorr (2009) on spray-dried lactobacilli. Moreover, results fit well with the outcomes of Corcoran et al. (2004) on strain LbGG: although LbGG showed an humble thermal tolerance in challenge tests, it exhibited a good survival during spray drying, confirming that thermal tolerance alone is not an accurate predictor of performance during spray drying and that other phenomena, such as dehydration, affect cell viability during drying. Actually, dehydration inactivation was associated with cell damage of Lactobacillus plantarum, rather than thermal inactivation, during drying (Lievense et al. 1994).

To get the most reliable quantification of the cells not injured by the heat exposure, a parallel approach was adopted. Quantification of undamaged cells provided evidence that over $10^{11}$ cells $\mathrm{g}^{-1}$ still presented a whole membrane. Data are in agreement with those reported by Corcoran et al. (2004) for cultures of LbGG in stationary phase of growth. Actually, the highest resistance of bacteria, if in stationary phase, has been associated with nutrient starvation (Santivarangkna et al. 2007) and to cross-protection conferred by the low $\mathrm{pH}$ attained during growth under uncontrolled $\mathrm{pH}$ conditions (Silva et al. 2005).

Both strains dried in CE were able to survive in simulated gastric juice, and as expected, the number of cells able to stand the acidic environment was the same obtained by undamaged cells quantification. Probiotics endurance is dependent on the spray-drying media applied, as differences in thermal conductivity and diffusivity can affect survival of spray-dried probiotics (Lian et al. 2002). CE is an aqueous solution of reducing sugars, proteins, minerals and soluble carbohydrates with differing degrees of polymerization (Blaiotta et al. 2013). As already reviewed by Crowe et al. (1998), the use of sugar as protectants of dehydrated biomaterials such as enzymes, proteins, liposomes, red blood cells and bacteria can alternatively be explained by the water-replacement hypothesis, which envisages the function of sugars as water substitutes when the hydration shell of proteins and water molecules around polar residues in membrane phospholipids are removed. The replacement leads to maintenance of phospholipids bilayers at their hydrated spacing, which in turn preserves the structure of the membrane, thereby preventing damage during drying or 
freezing (Ananta et al. 2005). On the other hand, the ability of sugars to stabilize proteins during drying is due to the aptitude of the sugars to form hydrogen bonds with the proteins when water is removed, and to, hereby prevent protein denaturation by maintaining the protein structure (Crowe et al. 1998; Ananta et al. 2005).

Loads obtained in this study were about two log higher than those reported by Corcoran et al. (2004) and Sunny-Roberts and Knorr (2009) for LbGG $\left(\sim 10^{9}\right.$ CFU $\left.\mathrm{g}^{-1}\right)$, but it has to be considered that a low ratio cells/carrier was used in the present study. In several studies, the influence of solids' concentration on the survival of micro-organisms during spray drying has been reported (Boza et al. 2004; Ananta et al. 2005).

To conclude, data provided an indication of the suitability of CE as carrier and protector during spray drying and a confirmation of the ability of CE to allow probiotic bacteria to withstand the environmental stresses in the human GIT, even in a dried form.

Spray-dried cultures of the two functional lactobacilli were incorporated in an anhydrous basis for chestnut mousse, stable at room temperature, developed ad hoc. Mousses have already been exploited as potential carriers for probiotic micro-organisms (Aragon-Alegro et al. 2007; Cardarelli et al. 2008; Buriti et al. 2010). In all cases, living bacteria were added to fresh mousses with the aim to develop a short shelf-life product, needing cold chain to be marked. Strains monitoring, up to 3 months, revealed that both lactobacilli in the anhydrous basis kept a population level higher than $8 \log \mathrm{CFU} \mathrm{g}^{-1}$. These amounts are comparable to those of milk-based probiotic products, for example bioyogurt, containing about $10^{6} \mathrm{CFU}$ of probiotic bacteria per $\mathrm{ml}$ at the end of their shelf life, which does not exceed 30 days when stored under refrigeration. In point of fact, according to Boylston et al. (2004) and to Laurens-Hattingh and Viljoen (2001), the recommended level of probiotic micro-organisms in food at the time of consumption should be at least $10^{6} \mathrm{CFU} \mathrm{g}{ }^{-1}$ to exert beneficial effects on the consumer's health. According to this criterion, chestnut mousse may represent a potential vehicle for the tested strains.

Moreover, according to sensorial analysis, all mousses exhibited a good acceptability and it was not possible to differentiate the control samples from the bacteriaadded products. Moreover, no significant difference was observed for overall impression, exhibiting in all cases a good range of evaluation ( $>6.5$ ratings). Actually, consumers' acceptance appeared to be related to creamy consistency as already highlighted by Elmore et al. (1999) for dairy desserts. Sensory results appeared in perfect agreement with those reported by Aragon-Alegro et al. (2007) for chocolate mousses or by Heenan et al. (2004) for frozen soy dessert supplemented with Lactobacillus acidophilus: in all cases, probiotic variants could not be distinguished from the control sample. On the other hand, other authors reported that probiotic micro-organisms affected the flavour of the food product to which they were added. In the survey of Cardarelli et al. (2008), flavour of the probiotic and the probiotic inuline added chocolate mousses was significantly different, when compared to the control product after 14 days of storage but not at 7 days of storage.

Results here reported suggest that chestnut mousse, a food product naturally rich in antioxidant compounds, is an excellent carrier for delivering probiotic strains. Anhydrous powders for preparing ready to be prepared chestnut mousses represent a simple formulation of a functional food in which the probiotic strains, manufactured under industrial conditions, are able to survive and to retain their functionality during storage.

To authors' knowledge, this is the first information on the survival of lactobacilli in an anhydrous basis for dessert: these initial assessments represent one of the possible applications of chestnut extract for probiotic strains protection along human GIT.

\section{Acknowledgements}

This work was supported by a grant from Regione Campania within the Program 'Castagna di Montella: valorizzazione e innovazione tecnologica sostenibile della filiera'. The authors thank Drs Federica Capobianco and Mario Coco for their technical collaboration.

\section{Conflict of interest}

No conflict of interest declared.

\section{References}

Ananta, E., Volkert, M. and Knorr, D. (2005) Cellular injuries and storage stability of spray-dried Lactobacillus rhamnosus GG. Int Dairy J 15, 399-409.

Aponte, M., Boscaino, F., Sorrentino, A., Coppola, R., Masi, P. and Romano, A. (2013) Volatile compounds and bacterial community dynamics of chestnut-flour-based sourdoughs. Food Chem 141, 2394-2404.

Aragon-Alegro, L.C., Alegro, A.J.H., Cardarelli, H.R., Chih Chiu, M. and Saad, S.M.I. (2007) Potentially probiotic and synbiotic chocolate mousse. LWT Food Sci Technol 40, 669-675.

Blaiotta, G., Di Capua, M., Coppola, R. and Aponte, M. (2012) Production of fermented chestnut purees by lactic acid bacteria. Int J Food Microbiol 158, 195-202.

Blaiotta, G., La Gatta, B., Di Capua, M., Di Luccia, A., Coppola, R. and Aponte, M. (2013) Effect of chestnut 
extract and chestnut fiber on viability of potential probiotic Lactobacillus strains under gastrointestinal tract conditions. Food Microbiol 36, 161-169.

Boylston, T.D., Vinderola, C.G., Ghoddusi, H.B. and Reinheimer, J.A. (2004) Incorporation of bifidobacteria into cheeses: challenges and rewards. Int Dairy J 14, 375-387.

Boza, Y., Barbin, D. and Scamparini, A.R.P. (2004) Effect of spray drying on the quality of encapsulated cells of Beijerinckia spp. Process Biochem 39, 1275-1284.

Buriti, F.C.A., Castro, I.A. and Saad, S.M.I. (2010) Viability of Lactobacillus acidophilus in synbiotic guava mousses and its survival under in vitro simulated gastrointestinal conditions. Int J Food Microbiol 137, 121-129.

Cardarelli, H.R., Aragon-Alegro, L.C., Alegro, J.H.A., de Castro, I.A. and Saad, S.M.I. (2008) Effect of inulin and Lactobacillus paracasei on sensory and instrumental texture properties of functional chocolate mousse. J Sci Food Agric 88, 1318-1324.

Chávez, B.E. and Ledeboer, A.M. (2007) Drying of Probiotics: optimization of formulation and process to enhance storage survival. Drying Technol 25, 1193-1201.

Collins, C.H., Lyne, P.M. and Grange, J.M. (1989) Counting microorganism. In Microbiological Methods eds. Collins, C.H., Lyne, P.M. and Grange, J.M. pp 127-140. Oxford, UK: Butterworth-Heinemann.

Corcoran, B.M., Rossi, R.P., Fitzgerald, G.F. and Stanton, C. (2004) Comparative survival of probiotic lactobacilli spray-dried in the presence of prebiotic substances. J Appl Microbiol 96, 1024-1039.

Crowe, J.H., Carpenter, J.P. and Crowe, L.M. (1998) The role of vitrification in anhydrobiosis. Ann Rev Physiol 60, 73-103.

De Vasconcelos, M.C.B.M., Bennett, R.N., Rosa, E.A.S. and Ferreira-Cardoso, J.V. (2010) Composition of European chestnut (Castanea sativa Mill.) and association with health effects: fresh and processed products. J Sci Food Agric 90, 1578-1589.

Elmore, J.R., Heymann, H., Johnson, J. and Hewett, J.E. (1999) Preference mapping: relating acceptance of creaminess to a descriptive sensory map of a semi-solid. Food Qual Pref 10, 465-475.

FAO/WHO. (2002) Guidelines for the evaluation of probiotics in foods. Food and Agriculture Organization of the United Nations and World Health Organization Expert Consultation Report. Food and Agricultural Organization of the United Nations and World Health Organization Working Group Report (online).

Gardiner, G.E., O’Sullivan, E., Kelly, J., Auty, M.A.E., Fitzgerald, G.F., Collins, J.K., Ross, R.P. and Stanton, C. (2000) Comparative survival rates of human-derived probiotic Lactobacillus paracasei and L. salivarius strains during heat treatment and spray drying. App Environ Microbiol 66, 2605-2612.

Heenan, C.N., Adams, M.C., Hosken, R.W. and Fleet, G.H. (2004) Survival and sensory acceptability of probiotic microorganisms in a nonfermented frozen vegetarian dessert. Lebensm Wiss Technol 37, 461-466.

International Dairy Federation Standard. (1993) Dried Milk and Dried Cream. Determination of Water Content. 26A. Brussels, Belgium.

Laurens-Hattingh, A. and Viljoen, B.C. (2001) Yogurt as probiotic carrier food. Int Dairy J 1, 11-17.

Lian, W., Hsiao, H. and Chou, C. (2002) Survival of bifidobacteria after spray-drying. Int J Food Microbiol 74, 79-86.

Lievense, L.C., Verbeek, M.A.M., Noomen, A. and van't Riet, K. (1994) Mechanism of dehydration inactivation of Lactobacillus plantarum. Appl Microbiol Biotechnol 41, 90-94.

Mauriello, G., Aponte, M., Andolfi, R., Moschetti, G. and Villani, F. (1999) Spray-drying of bacteriocin-producing lactic acid bacteria. J Food Prot 62, 773-777.

Meng, X.C., Stanton, C., Fitzgerald, G.F., Daly, C. and Ross, R.P. (2008) Anhydrobiotics: the challenges of drying probiotic cultures. Food Chem 106, 1406-1416.

Mussatto, S.I. and Mancilha, I.M. (2007) Non-digestible oligosaccharides: a review. Carbohydr Polym 68, 587-597.

Nagpal, R., Kumar, A., Kumar, M., Behare, P.V., Jain, S. and Yadav, H. (2012) Probiotics, their health benefits and applications for developing healthier foods: a review. FEMS Microbiol Lett 334, 1-15.

Ranadheera, R.D.C.S., Baines, S.K. and Adams, M.C. (2010) Importance of food in probiotic efficacy. Food Res Int 43, $1-7$.

Saarela, M., Lahteenmaki, L., Crittenden, R., Salminen, S. and Mattila-Sandholm, T. (2002) Gut bacteria and health foods - the European perspective. Int J Food Microbiol 78, 99-117.

Santivarangkna, C., Kulozik, U. and Foerst, P. (2007) Alternative drying processes for the industrial preservation of lactic acid starter cultures. Biotechnol Prog 23, 302-315.

Santivarangkna, C., Kulozik, U. and Foerst, P. (2008) Inactivation mechanisms of lactic starter cultures preserved by drying processes. J Appl Microbiol 105, 1-13.

Silva, J., Carvalho, A.S., Ferreira, R., Vitorino, R., Amado, F., Domingues, P., Teixeira, P. and Gibbs, P.A. (2005) Effect of the $\mathrm{pH}$ of growth on the survival of Lactobacillus delbrueckii subsp. bulgaricus to stress conditions during spray-drying. J Appl Microbiol 98, 775-782.

Silva, J., Freixo, R., Gibbs, P. and Teixeira, P. (2011) Spraydrying for the production of dried cultures. Int J Dairy Technol 64, 321-335.

Sunny-Roberts, E.O. and Knorr, D. (2009) The protective effect of monosodium glutamate on survival of Lactobacillus rhamnosus GG and Lactobacillus rhamnosus E-97800 (E800) strains during spray-drying and storage in trehalose-containing powders. Int Dairy J 19, 209-214.

Teixeira, P., Castro, H. and Kirby, R. (1996) Evidence of membrane damage lipid oxidation of spray-dried 
Lactobacillus bulgaricus during storage. Lett Appl Microbiol 22, 34-38.

UNI 10957. (2003) Sensory analysis - Method for establishing a sensory profile in foodstuffs and beverages.

Ying, D.Y., Sun, J., Sanguansri, L., Weerakkody, R. and Augustin, M.A. (2012) Enhanced survival of spray-dried microencapsulated Lactobacillus rhamnosus GG in the presence of glucose. J Food Eng 109, 597-602.

Zayed, G. and Roos, Y.H. (2004) Influence of trehalose and moisture content on survival of Lactobacillus salivarius subjected to freeze-drying and storage. Process Biochem 39, 1081-1086. 